\section{Medical Visitors}

\section{DeAr Sirs}

The Lord Chancellor's Department is shortly to advertise for a Medical Visitor to undertake special visits for the Court of Protection in the Principality of Wales. England and Wales is presently covered by five Visitors, appointed under S.102 of the Mental Health Act, 1983.

In 1982 the responsibility for interviewing and examining many cases was transferred to non-medically qualified civil servants. The LCD thereby saved a significant percentage of the costs of the Court as the hitherto full-time Medical Visitors were then invited to continue in a part-time capacity. This change had been planned for years, yet my Committee received less than three weeks' notice of it.

The sum offered to the Medical Visitor per visit was derisory in comparison with other part-time payment for central government work, including other work for the LCD. Despite our representations over four years it remains so.

Any Member of the British Medical Association who is interested in the work of a Medical Visitor is strongly advised to contact me at the address below.

J. R. A. ChAWNER

Chairman

Private Practice \& Professional Fees Committee

British Medical Association House

Tavistock Square, London WCI

\section{Overseas graduates and the MRCPsych}

DEAR SIRS

The Bulletin has, in recent months, published papers on the performance of overseas graduates in the MRCPsych examinations, ${ }^{1.2}$ and on their circumstances, career-wise, after they have been successful in the final examinations. ${ }^{3}$ This expressed concern of the College for the welfare of overseas graduates is very commendable, and I hope will go a long way towards assuring them that the College has their interest very much at heart. The surveys were initiated by, or emanated from, the Collegiate Trainees Committee, the Chief Examiner, and the Overseas Trainees Sub-committee.

I actually did hope, on reading the papers by Dr White and Professor Cawley, to find the greater failure rate of overseas doctors explained. Alas, this was not to be. For, in his Summary, the Chief Examiner stated 'It is not possible to pinpoint specific causes of failure' (my italics).

One would have thought that the pinpointing of the causes of the overseas doctors' higher failure rate was the essence of the whole exercise. I do appreciate that it is a very difficult thing to do, but feel that the Chief Examiner and the Chairman of the Collegiate Trainees' Committee should at least have attempted to answer the basic question. Surely, it is not impossible to figure out why people fail examinations?

People fail examinations because (a) they have insufficient information for the written work; (b) they are deficient in clinical skills; (c) they are unable to sustain a discussion at the orals; (d) though well informed, clinically competent and ordinarily able to discuss a wide range of subjects, they are overcome by anxiety and self-doubt on the big day; (e) they generally lack 'examination tochniques', or (f) the examiners deliberately mark themi down in the written work, harass them in the clinicals, or fire questions at them, at machine-gun rate, in the orals, to ensure their failure. This may be because the examiners disapprove of the candidates' race, religion, attire, country of origin, political inclinations or accent.

This study has now gone so far, that to retreat would be even harder than to proceed. Therefore, having started, let us finish. Would the Chief Examiner and the Chairman of the Collegiate Trainees' Committee consider repeating this exercise, to try to obtain data on the possible causes of failure listed above? Item (d) would be very difficult to quantify, but I think that most candidates would be willing to supply a self-rating of their emotional states during the examinations; item (f) would also require an honest contribution from the examiners, as to what their feelings were towards the candidates they examined. But if this further work can be done, it would ultimately give real meaning to this search, and identify the forms of assistance most appropriate to those in difficulty.

\section{Walrond Avenue \\ Wembley, Middlesex}

IKECHUKWU AZUONYE

WHITE, P. (1986) Why do overseas trainees fail? Bulletin of the Royal College of Psychiatrists, 10, 59-60.

${ }^{2}$ CAWLEY, R. H. (1986) Overseas graduates and the MRCPsych. Bulletin of the Royal College of Psychiatrists, 10, 60-63.

${ }^{3}$ Bhate, S., SAgovsky, R. \& Cox, J. L. (1986) Career survey of overseas psychiatrists successful in the MRCPsych. Bulletin of the Royal College of Psychiatrists, 10, 121-123.

\section{DeAr Sirs}

Dr Azuonye quotes me as saying that it is not possible to pinpoint specific causes of failure. In my paper I continued 'the MCQ's are not specifically to blame, nor are the essays; nor in the Membership Examination is the clinical'. This conclusion followed fairly detailed analysis of reasons for failure in the Autumn 1984 examinations. It is worth recalling that the MCQ papers are marked by a computer which knows nothing of sex, race, religion, or countries of origin; the essay papers are marked by two independent examiners, neither of whom knows more about the candidate than his/her number.

The first three of Dr Azuonye's proposed causes of failure pertain to educational matters rather than the examination. His fourth point is interesting but difficult to substantiate. Many candidates from all backgrounds experience anxiety and self-doubt before and during examinations. It has always been so, It is even claimed, on good authority, that people tend to give of their best in challenging tasks only if they experience at least a degree of anxiety. Dr Azuonye's hypothesis, which he would have us test, is that overseas candidates are more bedevilled by anxiety and self-doubt in the clinicals and orals than are indigenous candidates. 